\title{
Evaluation of fuel-switching opportunities in the residential sector
}

\author{
Aníbal T. De Almeida ${ }^{\mathrm{a}, *}$, Ana Lopes ${ }^{\mathrm{b}}$, Anabela Carvalho ${ }^{\mathrm{c}}$, Jorge Mariano ${ }^{\mathrm{c}}$, Catarina Nunes $^{\mathrm{a}}$ \\ a Department of Electrical Engineering, University of Coimbra, Polo II, 3030-290 Coimbra, Portugal

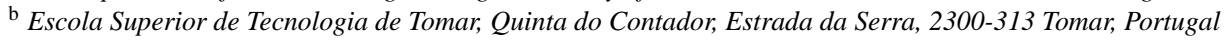 \\ c Instituto Superior de Engenharia de Coimbra, Quinta da Nora, Apartado 10057, 3031-601 Coimbra, Portugal
}

Received 4 November 2003; accepted 13 November 2003

\begin{abstract}
The aim of this paper is to analyse the impact of different natural gas and electricity end-use technologies in the residential sector, which compete among themselves in terms of energy consumption and carbon emissions. The analysis of 17 different technology options, which were chosen in order to match the consumption behaviour of a typical Portuguese family, has shown that the use of electric heat pumps, both for space and water-heating, combined with the use of a natural gas cooker, leads to the lowest energy consumption and to the lowest environmental impacts in terms of carbon emissions. Considering only the running costs, this choice is $45 \%$ more economic than having a natural gas centralised heating system combined with a gas cooker, and is $60 \%$ more economic than having an electric resistance space heater combined with an electric storage water heater and electric cooker, which is the worst case. The life cycle cost (LCC) analysis shows that the economic optimum is reached by the combination of a natural gas water heater with an electric storage space heater, and a natural gas cooker. The cost of conserved carbon (CCC) analysis shows that the combination of an electric heat pump water heater with an electric storage space heater, and a natural gas cooker is the best option in terms of environmental performance.
\end{abstract}

(c) 2003 Elsevier B.V. All rights reserved.

Keywords: Fuel-switching; Energy-efficiency; Natural gas conservation; Electricity; Space-heating; Water-heating; Cooking; Carbon emissions; Residential sector

\section{Introduction}

The examination of the European energy consumption trends shows that the consumption of energy in Portugal is growing at a faster rate over the past few years [1], with $4.5 \%$ per year whereas the European growth rate average is around $1 \%$ per year. The transportation sector was the responsible for the highest increase, followed by the services and the residential sector [2]. This situation was due, on one side, to the search for better comfort levels associated with higher disposable income, and on the other side, to the use of inefficient technologies, especially electricity end-use technologies. In the last decade, the electricity growth rate in the residential sector was around $7 \%$ per year. In the nineties, in order to achieve a better energy diversification, and in particular to reduce the dependency on oil, the European Union promoted the introduction of natural gas in Southern Europe [3].

\footnotetext{
* Corresponding author. Tel.: +351-239-796-218; fax: +351-239-406-672.

E-mail address: adealmeida@isr.uc.pt (A.T. De Almeida).
}

The energy diversification and the rational use of energy were only considered as relevant issues in the European energy policy after the first oil crisis in 1973. By this time, and in order to minimise the impact of a future crisis, the European Community has decided to develop a strategy plan concerned with the European Union supply side policy. Since then, natural gas consumption has been increasing very rapidly. Natural gas provides energy diversification and, when compared with other competing forms of energy such as coal, oil, or electricity produced in fossil fuel-based power plants, natural gas can significantly reduce the carbon emissions and almost eliminate the $\mathrm{SO}_{2}$ emissions [3]. However, this study shows that these conclusions are not so linear, since the environmental impacts are not only dependent on the energy type, but they are also strongly dependent on the end-use technology efficiency. The results show that in many cases the use of high-efficiency electric technologies has not only lower running costs, but also causes less damage in the environment.

In Portugal, although the first consumers were connected at the end of 1997 [3], in 2000, natural gas already represented $10 \%$ of the total energy consumption. As a term of comparison, in Spain natural gas has been used for 30 years 
and it only represents $12 \%$ of the total energy consumption. The market provisions forecast that around 1 million of residential consumers, representing $30 \%$ of the residential consumers in Portugal, are connected to natural gas in 2010. This fuel-switching scenario is the result of very aggressive marketing campaigns, which presents natural gas as a cheap and clean type of energy.

In the services and residential sectors, fuel switching from other competing forms of energies, including electricity, to natural gas was the most significant measure to increase the gas consumption, and was not accompanied by education of the consumer on how to make cost-effective options. However, fuel switching may not be the best measure for reducing primary energy consumption, since several of the electrical technologies (especially for space and water-heating) have become significantly more efficient, meaning that the use of electricity may be cleaner and cheaper than the use of natural gas. Additionally, the aggressive marketing campaigns, which were carried out after the introduction of natural gas, motivate people to consume without moderation.

A relevant issue, when assessing the fuel-switching impacts, is concerned with the European Union ratification of the Kyoto protocol. According to the most recent forecasts on the Portuguese carbon emission levels, in 2010, Portugal would go beyond the level allowed by the European Union (the carbon emission levels would be exceeded in 11 Mtons of $\mathrm{CO}_{2}$ ) [2]. To avoid this situation, the Portuguese Government and other actors from the energy market must implement adequate measures in order to change the energy consumption patterns in all the economy sectors, especially in the transportation, services, and residential sectors, whose consumption trends are characterised by the largest growth rates.

\subsection{Methodology}

The characterisation of the residential energy consumption was based on the results of the CArbon dioxide from Domestic equipment: ENd-use efficiency and Consumer Education (CADENCE) study [1], which were based in audits carried out before and after the introduction of natural gas, in the northern and central region of Portugal. The results were combined with data available from other sources, such as: the electricity utility company-Electricidade de Portugal (EDP) [4-6], which was based upon 3000 audits, and from the Directorate General of Energy [7].

Based in those results, an annual average consumption was defined for each residential end-use, including, water-heating, space-heating and cooking, in order to define an energy consumption pattern. Both the average useful and absorbed energy values were calculated.

Based in both the audit results and market availability, 17 competitive technology mix options were selected. For this definition two essential issues were considered: in first place consumers' most common options and in second place the most efficient technologies.
The 17-technology options were submitted to an economic and environmental evaluation, considering both the type of energy used and the conversion efficiency.

Finally, a payback analysis and a cost of conserved carbon (CCC) analysis were carried out for the most attractive options. Based on the final results, which included the life cycle cost (LCC) and the cost of the conserved carbon, a ranking of the different options was made.

\section{Characterisation of the residential energy consumption}

This section characterises a typical residence consumption pattern, which is based in the CADENCE European study [1], which was the basis for the technology scenario analysis.

The following section presents main findings of the CADENCE study, which are essentially concerned with household construction characteristics, types of end-use equipment, performance, and penetration.

\subsection{Residence type and some construction characteristics}

According to the National Institute of Statistics (INE) the average number of persons per household in Portugal is 3.2 [8]. The residences submitted to the audit presented a useful average area of $127 \mathrm{~m}^{2}$. The smallest house presented an area of around $80 \mathrm{~m}^{2}$ and the largest one presented an area of around $210 \mathrm{~m}^{2}$. Also, $80 \%$ of the audits were carried out in apartments [1]. An average of 5 rooms per residence was also observed (it is important to notice that this result is slightly above the National average, which is 4.5 rooms per residence [8]).

Around $90 \%$ of the analysed residences are 10-30 years old. Only in 1990, a thermal insulation building standard was published. Therefore, the average house insulation performance is modest with most of the houses featuring single-pane windows with aluminium frame. About half of the houses have a double outside wall with air cavity, with the other half having a single outside wall.

\subsection{Type of end-use equipment}

\subsubsection{Water-heating technologies}

Before the introduction of natural gas, $24 \%$ of all consumers used gas water heaters and $76 \%$ of all consumers used electric water heaters. The audit results showed that after the introduction of natural gas, $44 \%$ of all consumers have decided to switch to a natural gas water heater and $8 \%$ to a natural gas combined water and central space-heating system. The remaining $24 \%$ of the consumers have decided to keep the electric storage water heater. This fuel-switching conversion market has originated a very positive effect on the quality of the equipment installation, since specialised technicians carry it out. The gas equipment was installed in suitable places, following strict safety guidelines, such as 
kitchens, balconies and terraces. Before the introduction of natural gas, $52 \%$ of the gas equipment was placed in storerooms and bathrooms.

Another interesting result was related with the equipment age. Before the introduction of natural gas about $25 \%$ of the electric water heaters were more than 20 years old. However, the decision to switch from an electric water heater to a natural gas water heater has been carried out mostly by consumers who were using almost new electric water heaters ( $<5$ years old). This attitude shows that the equipment age is not a decisive factor to the consumers, when there is a fuel-switching opportunity.

\subsubsection{Space-heating technologies}

In Portugal, the energy used in residential space-heating systems is small, especially when compared with other European Union States with similar weather conditions, like Spain, Italy or Greece. This situation is due to two main reasons: Portugal has a milder climate almost all the year, and comfort levels are lower [3].

Concerning the first reason, it is a fact that in most of Portugal the climate can be considered as cold only in 4 months of a year (from middle of November to middle of March), and in the coastal strip the number of cold days is even less. However, the total lack of heating systems in the cold months may lead to situations of severe discomfort. In addition to this fact, older buildings have poor thermal insulation.

This situation has started to change in recent years, due to higher disposable income and because many new houses have central space-heating systems. The introduction of natural gas had a decisive role in this changing scenario, since many gas utilities had aggressive marketing campaigns, which include the promotion of this type of equipment. Bearing in mind the above-mentioned facts, it is easier to understand the audit results, which are confirmed by other sources [4-7]. In fact, before the introduction of natural gas $70 \%$ of all consumers used independent electric heaters to warm their houses during the winter. Around $15 \%$ of all consumers used a fireplace, of which only $27 \%$ were equipped with heat recovery. Also a significant part of the consumers, about $15 \%$, used gas independent heaters. After the introduction of natural gas, $8 \%$ of all consumers decided to install central water- and space-heating systems.

\subsubsection{Cooking technologies}

With the arrival of natural gas, consumers who had propane or butane gas cookers, around $32 \%$ of all users, opted to convert them to natural gas. Due to the heavy demand charges, the penetration of full electric cookers is quite small (4\%). These consumers did not choose to change to natural gas, since it would be necessary to invest in a new gas cooker. The remaining $64 \%$ of all consumers, who had a mixed cooker, (works with both, electricity and gas) also opted to keep and convert the gas part to natural gas. The electric plates of the mixed cookers are used only when the gas supply fails.

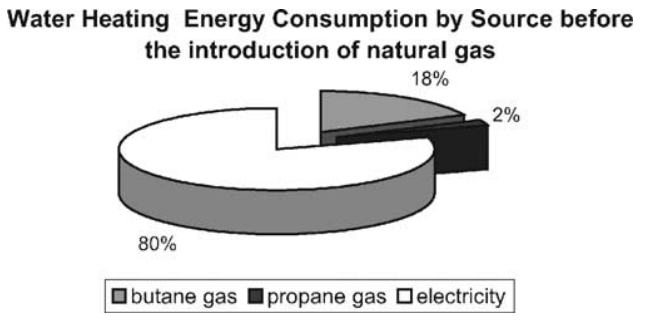

Fig. 1. Water-heating energy consumption before the introduction of natural gas.

\subsection{Levels of residential consumption}

These results characterise the situation before and after the introduction of natural gas. The energy options considered for this analysis are: electricity, bottled butane gas, bottled propane gas, piped propane gas and natural gas.

\subsubsection{Consumption before the introduction of natural gas}

The market studies have shown that butane or propane gas water heaters, and electric water heaters were the two types of appliances used for water-heating in most of the houses. Solar water heaters are used only in $2 \%$ of the houses, but in most cases there is a back-up electric resistance in the storage tank. Water-heating energy consumption by source is presented in Fig. 1.

The average annual water-heating consumption was found to be around $5.9 \mathrm{GJ}$ per residence.

Concerning with the space-heating energy consumption, an average annual consumption of $7.5 \mathrm{GJ}$ per residence was determined. The average energy consumption for space-heating in houses heated with electricity is around 5.4 GJ.

Fig. 2 shows the energy consumption of cooking appliances by source. The average annual cooking energy consumption was found to be around 3.4 GJ.

\subsubsection{Consumption after the introduction of natural gas}

In this section, a consumption analysis of natural gas appliances, both for water- and space-heating as well as for cooking, is presented.

Concerning water-heating, two types of appliances were considered, gas water heaters and central heating boilers, which represented the options of the consumers, who

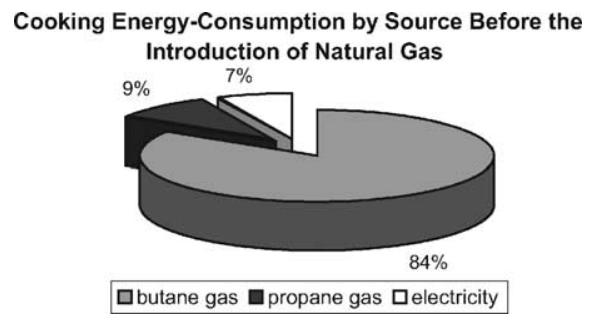

Fig. 2. Cooking energy consumption before the introduction of natural gas. 
switched to natural gas ( $76 \%$ of all consumers). About $8 \%$ of the consumers had opted to install a natural gas central heating system. The remaining consumers $(68 \%)$ chose a gas water heater. The consumers, who had opted for a natural gas water heater, showed an average annual consumption of $5.9 \mathrm{GJ}\left(150 \mathrm{~m}^{3}\right.$ of natural gas) per residence, which corresponds to a daily consumption of around 1001 of water, and is similar to the consumption before fuel switching.

The residences equipped with a gas boiler presented an average annual consumption of around $26.4 \mathrm{GJ}$ (about $700 \mathrm{~m}^{3}$ of natural gas per year), which includes a space-heating consumption of around $20.9 \mathrm{GJ}$ per year $\left(550 \mathrm{~m}^{3}\right.$ of natural gas per year). The availability of gas central heating led to a significant increase in the energy consumption for space-heating. For cooking appliances, an average annual consumption of $4 \mathrm{GJ}$ (about $100 \mathrm{~m}^{3}$ of natural gas per year) per residence was determined, showing a moderate increase since the conversion of natural gas.

\section{Definition of competing technology options}

A Portuguese family typically uses the following technologies:

- gas water heater or electric water heater for water-heating end-uses;

- independent electric heaters, independent gas heaters, fireplaces or, in a very small percentage, gas centralised space-heating system for space-heating end-uses;

- gas cooker, electric cooker or mixed (gas plus electricity) cooker for cooking.

Microwave ovens are also used in Portugal. However, they are essentially used for warming drinks or food. Since this type of technology is not usually used in food preparation, it was decided to exclude it from the analysis.

The aim of this section is to present competitive mixes of technology options that would meet the consumer needs. Based on this assumption, the following competitive mixes of technology options were defined, and are presented in Table 1. These options will be considered in the economical and environmental analysis to select the best mixes.

Air-to-air heat pumps have traditionally been used for space conditioning (both heating and cooling), but air-to-water heat pumps are now also being used for electric water-heating. In Portugal, heat pumps water heaters (no air conditioning capabilities) have a small penetration because of their high cost compared with conventional water heaters (gas or electric resistance). They are much more efficient than electric resistance water heaters, and in Portugal due to the mild weather, they can achieve an average coefficient of performance (COP) of 4. Contrary to solar collectors which require access to a southern facing roof or wall, heat pump water heaters can be installed in practically any type of dwelling in regions with mild winters. This is
Table 1

Competitive technology options

\begin{tabular}{ll}
\hline Option & Technology (water-heating, space-heating, cooking) \\
\hline A-1 & Natural gas (NG) central water- and space-heating system, \\
& NG cooker \\
A-2 & NG water heater, NG wall furnace, NG cooker \\
B-1 & NG water heater, independent electric heater, NG cooker \\
B-2 & NG water heater, independent electric storage heater (ESH), \\
& NG cooker \\
B-3 & NG water heater, electric heat pump, NG cooker \\
C-1 & Electric water heater, independent electric heater, NG cooker \\
C-2 & Electric water heater, independent ESH, NG cooker \\
C-3 & Electric water heater, electric heat pump, NG cooker \\
C-4 & Electric heat pump, independent electric heater, NG cooker \\
C-5 & Electric heat pump, independent ESH, NG cooker \\
C-6 & Electric heat pump, electric heat pump, NG cooker \\
D-1 & Electric water heater, independent electric heater, electric \\
& cooker \\
D-2 & Electric water heater, independent ESH, electric cooker \\
D-3 & Electric water heater, electric heat pump, electric cooker \\
D-4 & Electric heat pump, independent electric heater, electric \\
& cooker \\
D-5 & Electric heat pump, independent ESH, electric cooker \\
D-6 & Electric heat pump, electric heat pump, electric cooker \\
\hline
\end{tabular}

the case of most of the Portugal territory. In colder regions, ground-source heat pumps may be more appropriate [12] although they are more expensive.

\subsection{Reference data}

The reference results for the technology-scenario analysis are presented in Table 2, which are based in the results presented in Section 2.3.2.

\subsection{Energy cost and carbon emissions for each tecnology option}

The calculation of the total energy cost for each technology option was based in the energy prices of the first quarter of 2002. Those values are presented in Table 3.

Concerning the energy prices presented in Table 3, the following considerations were taken into account:

- The dual rate electric energy price was only considered for options B-2, C-2, C-5, D-2 and D-5, in which electric storage space heaters are used.

- It was assumed that the consumers who opted for natural gas for space and water-heating as well as for cooking (A-1 or A-2 options) would only need $3.45 \mathrm{kV}$ A as the maximum demand. Since electric energy is used in other domestic appliances and lighting, the electric demand charge was not considered as an expense for these options.

- For the remaining cases, it was assumed that the consumers would need to have a maximum demand of $6.9 \mathrm{kV}$ A. Since the first $3.45 \mathrm{kV}$ A are required for appliances which must use electricity, only the extra demand 
Table 2

Reference data per residence

\begin{tabular}{|c|c|c|c|c|}
\hline End-uses & Efficiency $(\%)$ & Water-heating (GJ) & Space-heating (GJ) & Cooking (GJ) \\
\hline Useful energy & & 4.6 & 16.8 & 1.5 \\
\hline NG central heating system & 80 & $5.9\left(150 \mathrm{~m}^{3}\right.$ of $\left.\mathrm{NG}\right)$ & $20.9\left(550 \mathrm{~m}^{3}\right.$ of $\left.\mathrm{NG}\right)$ & \\
\hline NG wall furnace & 85 & & $19.7\left(520 \mathrm{~m}^{3}\right.$ of $\left.\mathrm{NG}\right)$ & \\
\hline Independent electric space resistance & 100 & & 16.8 & \\
\hline Independent electric storage space resistance & 100 & & 16.8 & \\
\hline Electric space-heating pump & 400 & & 5.4 & \\
\hline NG water heater & 80 & $5.9\left(150 \mathrm{~m}^{3}\right.$ of $\left.\mathrm{NG}\right)$ & & \\
\hline Independent electric storage water heater & 80 (includes stand-by losses) & 5.9 & & \\
\hline Electric water-heating pump & 400 & 1.1 & & \\
\hline NG cooker & 38 & & & 4.0 \\
\hline Electric cooker & 43 & & & 3.6 \\
\hline
\end{tabular}

NG: natural gas.

Table 3

Energy prices in the first quarter of 2002

\begin{tabular}{|c|c|c|}
\hline & Fixed rate (euro per month) & Variable rate $\left(\mathrm{euro} / \mathrm{m}^{3}\right)$ \\
\hline \multirow[t]{3}{*}{ Natural gas price (scale D1) } & 0.78 & 0.62 \\
\hline & \multicolumn{2}{|l|}{ Variable rate } \\
\hline & Intermediate peak (euro/kWh) & Off-peak (euro/kWh, 10 p.m. -8 a.m.) \\
\hline Electric energy price (simple rate) & 0.090 & 0.090 \\
\hline Electric energy price (simple rate) & 0.090 & 0.090 \\
\hline Electric energy price (dual rate) & 0.090 & 0.050 \\
\hline \multirow[t]{7}{*}{ Electric energy price (dual rate) } & 0.090 & 0.050 \\
\hline & \multicolumn{2}{|l|}{ Demand charge } \\
\hline & $\mathrm{kV} \mathrm{A}$ & Euro per month \\
\hline & 3.45 & 5.08 \\
\hline & 6.9 & 11.24 \\
\hline & 3.45 & 7.06 \\
\hline & 6.9 & 13.22 \\
\hline
\end{tabular}

charge increase was considered, which amounts to 6.16 euro $^{1}$ for both simple and dual rate.

Concerning the carbon emission values associated with the use of natural gas, a value of 0.055 ton of $\mathrm{CO}_{2}$ per GJ (2.07 ton of $\mathrm{CO}_{2}$ per $10^{3} \mathrm{~m}^{3}$ of natural gas) was assumed; for electric energy $370 \mathrm{~g}$ of $\mathrm{CO}_{2}$ per $\mathrm{kWh}$ was assumed in the emission calculations. This value is related with electricity produced in natural gas based combined cycle gas turbine (CCGT) power plants. The vast majority of the electricity generation expansion in Southern Europe is being carried out with CCGT plants due to their high efficiency and reduced emissions, when compared with other fossil fuel plants.

Based on these assumptions, the energy cost and the carbon emission analysis was carried out for each option. The results are presented in Fig. 3.

As observed in Fig. 3, in terms of energy costs, the two most economic options are, in descending order, the combination of electric heat pumps for both space- and

\footnotetext{
${ }^{1}$ Euro is the European Union currency. One euro is equal to 1.18 US dollar in October 2003.
}

water-heating, and natural gas cooker-C-6 (280 euro per year), and the combination of electric heat pumps for both space- and water-heating, and electric cooker-D-6 (294 euro per year). The two options with the highest energy costs are the combination of an electric water heater with an electric resistance space heater, and an electric cooker-D-1 (718 euro per year), and the combination of an electric water heater with an electric resistance space heater, and a natural gas cooker-C-1 (704 euro per year). Space-heating is the common reason for the difference between the most economic and the most expensive options, in terms of running costs. The electric heat pump space heater is common to the three options with lowest running costs, and the room electric heaters are used in the three most expensive options, leading to more than twice the energy cost of the most economic option.

The results obtained for the carbon emission levels are similar. The two most environment-friendly options are, in descending order, $\mathrm{C}-6$ ( 0.76 tons of $\mathrm{CO}_{2}$ per year), and D-6 (0.91 tons of $\mathrm{CO}_{2}$ per year). The two most pollutant options are D-1, and D-2 (both with 2.67 tons of $\mathrm{CO}_{2}$ per year). These options are equivalent in terms of emission 
Energy Cost and Carbon Emissions for each Technology Options

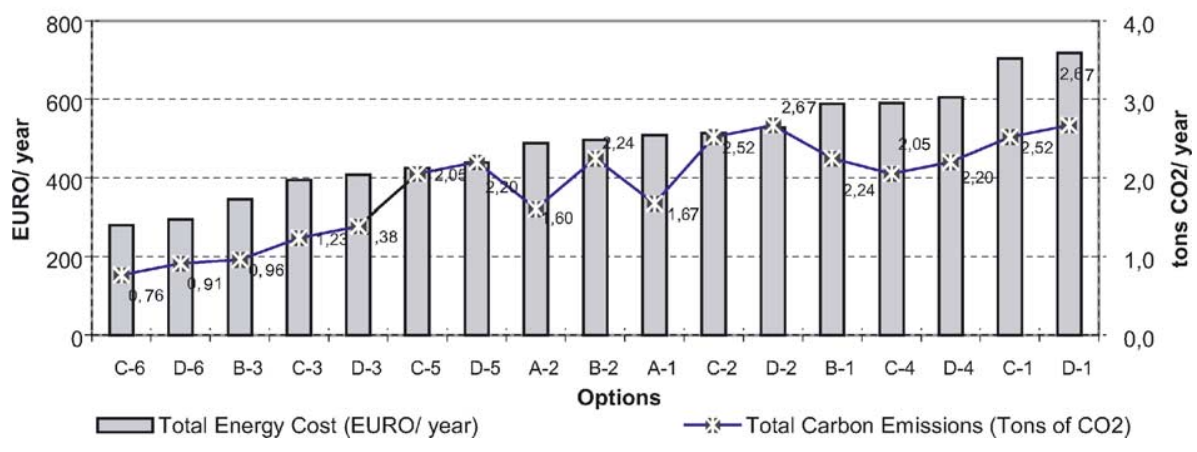

Fig. 3. Energy cost and carbon emissions for each technology option.

levels, since the storage space heater is responsible for shifting the consumption to the off-peak hours, but uses the same amount of electricity. The load shifting results in a lower energy cost, but the emission levels remain the same. Finally, the difference between the smallest and the largest carbon emission options is very significant, since options D-1 and D-2 are around 3.5 times more pollutant than option C-6, which is the most environment-friendly option. The primary results clearly show that natural gas technologies are neither the most economic in terms of running costs, nor even the most environment-friendly options. Technology options including heat pumps for spaceand water-heating showed the best performance, both on economic and on environmental perspectives. On the other side, resistive-electric technology options, such as option C-1, D-1 and D-2, presented the worst results. This means that the energy type by itself is not enough to analyse the environmental and economical impacts, since the balance is strongly dependent on the end-use technology efficiency.

\section{Economic and environmental analysis}

In this section, an economic and environmental analysis, considering equipment costs, is carried out. In the first place, a simple payback analysis is presented. The next step was related with the calculation of the life cycle cost of the selected technologies as a function of several factors, such as: capital investment, saved energy, and emission levels. Finally, the cost of conserved carbon analysis was also carried out.

\subsection{Simple payback analysis}

In Portugal, the incentives to promote the end-uses addressed in this paper were limited to electric storage heaters. The distribution electric utility, EDP, promotes this type of equipment, by offering a discount of $10 \%$, which was considered in the economic analysis presented in this sub-section.

Before the simple payback analysis, a first selection of options was carried out. The basis for this selection is as it follows: for the same investment level, only the options with the best performance (either in terms of energy costs
Table 4

First technology option selections

\begin{tabular}{llll}
\hline Option & $\begin{array}{l}\text { Total } \\
\text { investment } \\
\text { (euro) }\end{array}$ & $\begin{array}{l}\text { Total energy cost } \\
\text { (euro per year) }\end{array}$ & $\begin{array}{l}\text { Total carbon } \\
\text { emission levels (tons } \\
\text { of } \mathrm{CO}_{2} \text { per year) }\end{array}$ \\
\hline$B-1$ & 820 & 587 & 2.24 \\
$\mathrm{C}-1$ & 820 & 704 & 2.52 \\
$\mathrm{D}-1$ & 820 & 718 & 2.67 \\
$B-2$ & 1350 & 496 & 2.24 \\
$\mathrm{C}-2$ & 1350 & 513 & 2.52 \\
$\mathrm{D}-2$ & 1350 & 527 & 2.67 \\
$A-2$ & 1550 & 488 & 1.60 \\
$C-4$ & 2820 & 590 & 2.05 \\
$\mathrm{D}-4$ & 2820 & 604 & 2.20 \\
$B-3$ & 3140 & 345 & 0.96 \\
$\mathrm{C}-3$ & 3140 & 393 & 1.23 \\
$\mathrm{D}-3$ & 3140 & 408 & 1.38 \\
$C-5$ & 3340 & 425 & 2.05 \\
$\mathrm{D}-5$ & 3340 & 439 & 2.20 \\
$A-1$ & 4190 & 508 & 1.67 \\
$C-6$ & 5140 & 280 & 0.76 \\
$D-6$ & 5140 & 294 & 0.91 \\
\hline
\end{tabular}

or carbon emissions) were considered for further analysis. These options are the italicised options in Table 4. Option D-6 was also considered for further analysis, because in this case all the equipment is electric, which may represent the consumers' choice, due to the lack of natural gas in some locations.

The second selection was based on the simple payback period of each technology option, shown in Table 5. The

Table 5

Simple payback analysis in relation to option B-1

\begin{tabular}{lclc}
\hline Option & $\begin{array}{l}\text { Investment } \\
\text { cost (euro) }\end{array}$ & $\begin{array}{l}\text { Energy cost } \\
\text { (euro) }\end{array}$ & $\begin{array}{l}\text { Payback } \\
\text { period (years) }\end{array}$ \\
\hline$B-1$ & 820 & 587 & \\
$B-2$ & 1350 & 496 & 5.7 \\
$A-2$ & 1550 & 488 & 7.3 \\
C-4 & 2820 & 590 & -766 \\
$B-3$ & 3140 & 345 & 9.6 \\
C-5 & 3340 & 425 & 15.5 \\
A-1 & 4190 & 508 & 42.6 \\
$C-6$ & 5140 & 280 & 14.0 \\
$D-6$ & 5140 & 294 & 14.7 \\
\hline
\end{tabular}


results for the payback analysis are assessed in relation to option B-1, which combines a natural gas water heater, with an electric resistance space heater, and a natural gas cooker. Option B-1 is considered as the reference option, since it has the lowest level of capital investment, and is the most widely used by the Portuguese consumers. Italicised options were selected for the final analysis.

It was possible to immediately exclude options C-5 (combination of an electric heat pump water heater, with an independent electric storage heater, and a natural gas cooker), and A-1 (combination of a natural gas central heating system, with a natural gas cooker), since the simple payback period was higher than 15 years, which is the equipment average lifetime. The combination of an electric heat pump water heater, with an electric resistance space heater, and a natural gas cooker-C-4 was also excluded because its investment cost is higher than the reference investment cost, and there are no cost savings in relation to B-1.

\subsection{Life cycle cost analysis}

A life cycle cost analysis was carried out for the remaining options. Life cycle cost is the sum of the purchase price (PP) with the discounted lifetime operating cost, which is equal to the annual operating cost (OC) times the present worth factor (PWF) $[9,10]$.

$$
\mathrm{LCC}=\mathrm{PP}+\mathrm{PWF}\left(\mathrm{LT}, i_{\mathrm{r}}\right) \mathrm{OC}
$$

PWF is used to compare payments at different time points, since it is necessary to relate them to the same time and to calculate their present value. For a series of yearly payments the present worth factor is defined as:

$\operatorname{PWF}\left(\mathrm{LT}, i_{\mathrm{r}}\right)=\frac{\left(1+i_{\mathrm{r}}\right)^{\mathrm{LT}}-1}{\left(1+i_{\mathrm{r}}\right)^{\mathrm{LT}} i_{\mathrm{r}}}$,

Where, LT is the equipment lifetime and $i_{\mathrm{r}}$ is the discount rate which follows as the difference of the nominal bank interest rate $i$ and inflation rate $e$ :

$i_{\mathrm{r}}=i-e$,

In this case an $i_{\mathrm{r}}$ of 0.05 and a LT of 15 years were considered, which leads to a value of 10.38 for the PWF.

During the energy and environmental impact analysis, which includes a comparison between different types of in- vestments and improvements, a calculation of the life cycle cost of the selected options was carried out, considering the additional purchase price to the consumer plus the present value of the sum of the annual savings. It is important to notice that in this case the operational costs are negative since they are related to energy savings. Following these considerations, Eq. (4) shows that:

$\Delta \mathrm{LCC}=\Delta \mathrm{PP}+\mathrm{PWF}\left(\mathrm{LT}, i_{\mathrm{r}}\right) \Delta \mathrm{OC}$

The variation of life cycle cost $(\triangle \mathrm{LCC})$ is defined as the sum of the purchase price increase $(\Delta \mathrm{PP})$ plus the present value of the annual operating cost savings ( $\triangle \mathrm{OC})$.

Bearing in mind the above considerations, the $\triangle \mathrm{LCC}$ as a function of the energy cost savings was plotted. The results are presented in Fig. 4.

If the operating costs were only the energy costs, then the economic optimum would be reached by the option B-2, which combines a natural gas water heater, with an independent electric storage heater, and a natural gas cooker, since it has the lowest $\triangle \mathrm{LCC}$. Furthermore, according with these results, also options A-2 (natural gas water heater, natural gas wall furnace, and a natural gas cooker), and B-3 (natural gas water heater, electric pump space heater, and a natural gas cooker) are able to compensate their additional investment costs due to their energy cost savings. The remaining options have a positive $\triangle \mathrm{LCC}$, which means that the energy cost savings are not enough to overcome the additional purchase price. Comparing options C-6 and D-6, which are the combination of electric heat pumps for both space and water-heating, with a natural gas cooker in the first case, and with an electric cooker in the second case, it is possible to conclude that option D-6 has a higher $\triangle \mathrm{LCC}$, but the energy savings are lower, which results in a less attractive option.

To complete this analysis, it is worth to consider a more comprehensive assessment of the operating cost, which includes an environmental cost. In several countries of the European Union, renewable energies receive a price premium corresponding to 75 euro per ton of avoided $\mathrm{CO}_{2}$ emissions. In this paper, it is proposed to give the same incentives to the saved energy, achieved through the use of energy-efficient technologies. The rationale for setting this type of incentives to promote energy-efficiency is based on the fact that $1 \mathrm{kWh}$ of energy saved reduces the emissions by the same amount

$\Delta \mathrm{LCC}$ as a function of the Energy Cost Savings

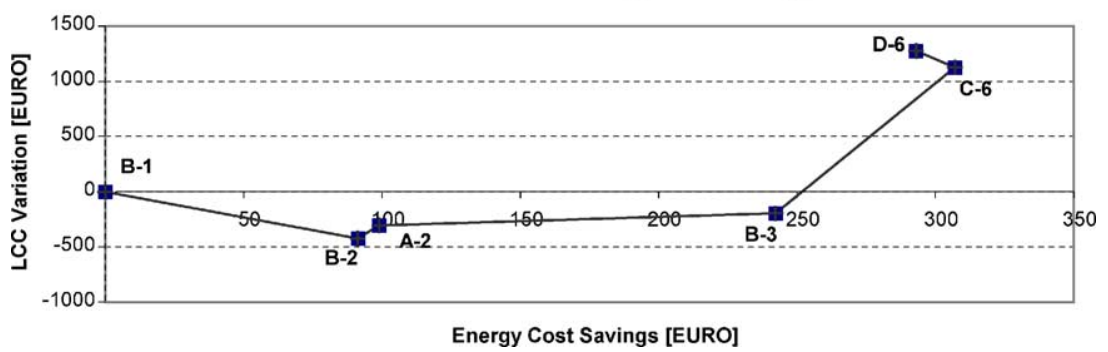

Fig. 4. Life cycle cost variation as a function of the energy cost savings, calculated in relation to the reference option (option B-1). 


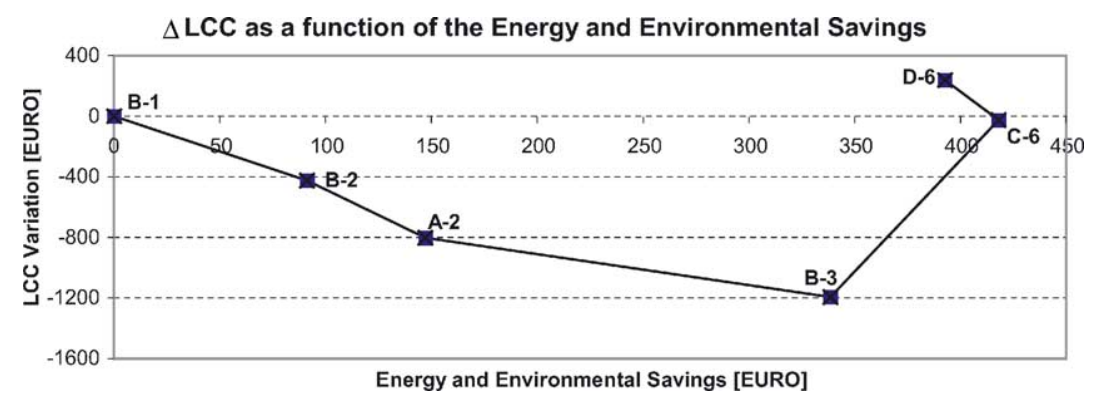

Fig. 5. Life cycle cost variation as a function of the energy and environmental cost savings, both calculated in relation to the reference option (option B-1).

as $1 \mathrm{kWh}$ generated by renewable energies. The results of the global costs are presented in Fig. 5.

When the environmental costs are considered, the results are significantly different from those presented in Fig. 4. The introduction of the environmental factor resulted in a significant improvement of the $\triangle \mathrm{LCC}$ of options A-2, B-3 and C-6. Option D-6 has also improved, but it is still not able to compensate its additional purchase price. In this situation, option B-3 reached the economic optimum, which emphasises its environmental performance.

\subsection{Cost of conserved carbon analysis}

The cost of conserved carbon analysis was performed. The cost of conserved carbon is defined as the ratio between the variation of the life cycle cost, including purchase and energy operating costs $(\triangle \mathrm{LCC})$, and the saved carbon emissions ( $\mathrm{SCE}$ in tons of $\mathrm{CO}_{2}$ per year) times the equipment lifetime (LT).

$\mathrm{CCC}=\frac{\Delta \mathrm{LCC}}{\mathrm{SCE} \times \mathrm{LT}}$

The cost of conserved carbon analysis is presented in Fig. 6 . However, options B-1 (base case) and B-2 were not considered, since there are no carbon savings associated with those options.

Observing Fig. 6, it is possible to conclude that options A-2 and B-3 are classified as win-win options and options C-6 and D6 as medium cost options. Although, option A-2 has the lowest price for carbon savings, it has to be stressed

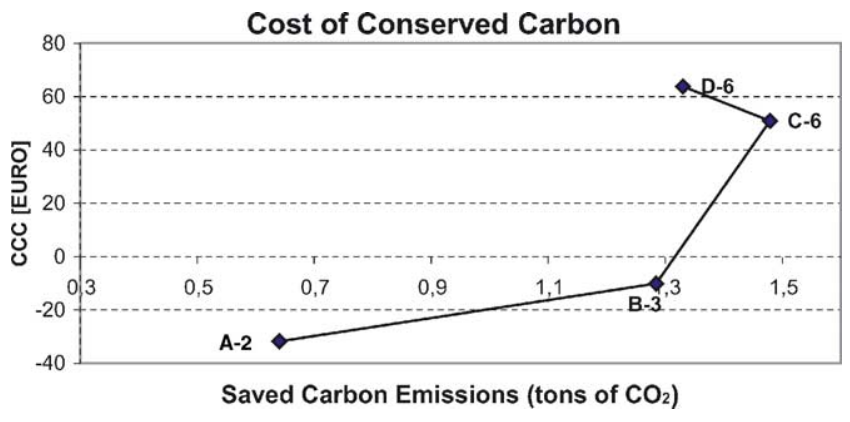

Fig. 6. Cost of conserved carbon. that this option is not responsible for a very significant reduction of carbon emissions.

\subsection{Some results in other countries}

The analysis of similar studies carried out in USA and other European countries has shown that the results of comparing gas and electric technologies is dependent of two main factors, namely the relative price of fuels and the weather conditions. A recent study carried out in Kansas State University (KSU) [11] shows heating costs as a function of several fuel prices and equipment efficiency. Taking into account the Portuguese electricity and natural gas prices, it is possible to conclude that the results of this study are consistent with those presented in [11]. The International Energy Agency Heat Pump Centre (IEA HPC) has also carried out several studies [12] that compared gas heating technologies with electric heat pumps (ground-source and air-source). In studies carried out in Switzerland, United Kingdom, and United States the results were diversified, being strongly dependent on fuel prices.

\section{Conclusions}

Natural gas is the least damaging fossil fuel at an environmental level, but it also produces carbon emissions. Furthermore, saying that the natural gas is less pollutant than other forms of energy may not be true, since it depends on the type of end-use technology that is being used to provide the energy service. This paper showed that the use of high-efficiency electric technologies can be more environment-friendly and more economical depending upon the relative fuel prices. A variety of competing technologies was assessed in terms of energy costs, emissions and life-cycle costs.

The variation of the life cycle cost, as a function of the equipment cost and the energy operating costs, showed that the combination (B-2) of a natural gas water heater, with an independent electric storage heater, and a natural gas cooker has the best economical performance. If the life cycle cost also includes the internalisation of the environmental operating costs, the combination (B-3) of a natural gas water 
heater, with an electric pump space heater, and a natural gas cooker leads to the economic optimum. The introduction of the environmental costs has also improved other options, which include the combination of electric heat pumps for both space- and water-heating.

The cost of conserved carbon analysis showed that option B-3 may be classified as the best option, concerning their environmental and economic performance. Although option A-2, which combines a natural gas water heater, with a natural gas wall furnace, and a natural gas cooker, has the lowest saved carbon cost, its contribution to the carbon emission savings is low. When compared with natural gas technologies, heat pumps for space- and water-heating lead to large energy and carbon emission savings. However, the heat pumps are costly and in some conditions their application is not cost-effective.

Options that include water-heating heat pumps are only attractive for consumers with higher levels of hot water consumption, since the additional purchase price of this type of equipment is very high. The cost of residential water-heating heat pumps is high due to the small sales volume. Due to their high potential to achieve large energy and carbon savings, suitable market transformation programs should be used to promote the large-scale penetration of this equipment. Regarding the environmental externalities, if in the future the European Union decides to increase the incentives to avoid $\mathrm{CO}_{2}$ emissions, in order to meet the Kyoto protocol commitments, carbon reducing technologies, like heat pumps, could receive an additional boost.

\section{References}

[1] B. Boardman, T. Fawcett, K. Lane, K. Blok, M. Brummelen, K. Eising, T. Almeida Aníbal, C. Nunes, J. Mariano, CADENCE-CArbon dioxide from Domestic equipment: ENd-use efficiency and Consumer
Education (CADENCE), SAVE contract no. XVII/4.1031/Z/97-181, European Commission, Brussels, Belgium, 1999.

[2] T. Almeida Aníbal, Ana Lopes, Anabela Carvalho, J. Mariano, A. Jahn, M. Broege, G. Gangas, D. Gidarokosta, Natural gas integrated resource planning, SAVE contract no. XVII/4.1031/Z/98-055, European Commission, Brussels, Belgium, 2000.

[3] Ministry of the Environment. PNAC-National Climate Change Programme (in Portuguese). Version 2001 for public discussion, Ministry of the Environment, Climate Change Commission, Lisbon, Portugal, 2001.

[4] EDP (Electric Portuguese Utility), Characterization of the energy consumption in the residential sector (in Portuguese), CCE (Energy Conservation Agency), EDP-Electricidade de Portugal, S.A., Lisbon, Portugal, 1994.

[5] EDP (Electric Portuguese Utility). Monitoring the energy consumption in the residential sector (in Portuguese), CCE (Energy Conservation Agency), EDP-Electricidade de Portugal, S.A., Lisbon, Portugal, 1996.

[6] EDP (Electric Portuguese Utility). Electricity consumption in water-heating end-uses (in Portuguese), CCE (Energy Conservation Agency), EDP-Electricidade de Portugal, S.A., Lisbon, Portugal, 1996.

[7] DGE (Directorate General of Energy). Energy consumption in the residential sector (in Portuguese), DGE, Ministry of Energy and Industry, Lisbon, Portugal, 1989.

[8] INE (National Institute of Statistics). National inquire on inhabitation (in Portuguese), National Institute of Statistics, Lisbon, Portugal, 1998. See also: http://www.ine.pt/prodserv/destaque/d0004052/d000405-2.html.

[9] M. Sakulin, E. Schmautzer, J. Adnot, M. Orphelin, Electric and storage water heaters-technical and economical analysis of energy efficiency improvement, in: Proceedings of DUEE ConferenceDomestic use of electrical energy, Cape Town, South Africa, 1997.

[10] H.E. Marshall, S.R. Petersen, Life cycle costing, in: Mechanical Estimating Guidebook for Building Construction, sixth ed., McGraw-Hill Inc., 1995, pp. 407-417.

[11] Kansas State University Engineering Extension, Comparing fuel costs of heating and cooling systems, KSU Engineering Extension, Manhattan, Kansas State, 2003. See also: http://www.engext.ksu.edu.

[12] IEA Heat Pump Centre. Case studies: Examples of heat pumps applications, International Energy Agency Heat Pump Centre (IEA HPC), Sittard, The Netherlands, 2003. See also: http://www. heatpumpcentre.org/cases/home.htm. 